\title{
Teen Pregnancy Risk Factors Among Young Women of Diverse Sexual Orientations
}

Brittany M. Charlton, ScD, a,b,c,d Andrea L. Roberts, PhD, e Margaret Rosario, PhD, ${ }^{f}$ Sabra L. Katz-
Wise, PhD, a,b Jerel P. Calzo, PhD,, Donna Spiegelman, ScD, ${ }^{, d, d, h}$ S. Bryn Austin, ScD,b,d,e

OBJECTIVES: Young women who are sexual minorities (eg, bisexual and lesbian) are approximately twice as likely as those who are heterosexual to have a teen pregnancy. Therefore, we hypothesized that risk factors for teen pregnancy would vary across sexual orientation groups and that other potential risk factors exist that are unique to sexual minorities.

METHODS: We used multivariable log-binomial models gathered from 7120 young women in the longitudinal cohort known as the Growing Up Today Study to examine the following potential teen pregnancy risk factors: childhood maltreatment, bullying victimization and perpetration, and gender nonconformity. Among sexual minorities, we also examined the following: sexual minority developmental milestones, sexual orientation-related stress, sexual minority outness, and lesbian, gay, and bisexual social activity involvement.

RESULTS: Childhood maltreatment and bullying were significant teen pregnancy risk factors among all participants. After adjusting for childhood maltreatment and bullying, the sexual orientation-related teen pregnancy disparities were attenuated; these risk factors explained $45 \%$ of the disparity. Among sexual minorities, reaching sexual minority developmental milestones earlier was also associated with an increased teen pregnancy risk.

ConcLusions: The higher teen pregnancy prevalence among sexual minorities compared with heterosexuals in this cohort was partially explained by childhood maltreatment and bullying, which may, in part, stem from sexual orientation-related discrimination. Teen pregnancy prevention efforts that are focused on risk factors more common among young women who are sexual minorities (eg, childhood maltreatment, bullying) can help to reduce the existing sexual orientation-related teen pregnancy disparity.

\footnotetext{
aDivision of Adolescent and Young Adult Medicine, Boston Children's Hospital, Boston, Massachusetts ${ }^{b}$ Department of Pediatrics, Harvard Medical School, Departments of ${ }^{C}$ Epidemiology, ${ }^{e}$ Social and Behavioral Sciences, and ${ }^{h}$ Biostatistics, Nutrition, and Global Health and Population, Harvard T.H. Chan School of Public Health, Harvard University, Boston, Massachusetts; ${ }^{d}$ Channing Division of Network Medicine, Department of Medicine, Brigham and Women's Hospital, Boston, Massachusetts; ${ }^{f}$ Department of Psychology, The Graduate Center, City University of New York, New York City, New York; and ${ }^{g}$ Division of Health Promotion and Behavioral Science, Graduate School of Public Health, San Diego State University, San Diego, California
}

Dr Charlton conceptualized the project, conducted the analyses, and led the development and writing of the article; Dr Austin supervised data collection; Drs Austin, Roberts, Rosario, Katz-Wise, Calzo, and Spiegelman aided in the interpretation of data and critically reviewed the manuscript for important intellectual content; and all authors approved the final manuscript as submitted and agree to be accountable for all aspects of the work.

This work was presented in part at the North American Society for Pediatric and Adolescent Gynecology Annual Clinical and Research Meeting; April 7-9, 2016; Toronto, Ontario; the Society for
WHAT'S KNOWN ON THIS SUBJECT: Compared with their heterosexual peers, young women who are sexual minorities (eg, bisexuals and lesbians) are at heightened teen pregnancy risk. Young sexual minority women report established risk factors for teen pregnancy, such as childhood maltreatment, more frequently than heterosexuals.

WHAT THIS STUDY ADDS: There is limited research in which researchers empirically examine whether teen pregnancy risk factors vary across sexual orientation groups. To our knowledge, no authors of US-based studies have explored whether there are also additional risk factors unique to sexual minorities.

To cite: Charlton BM, Roberts AL, Rosario M, et al. Teen Pregnancy Risk Factors Among Young Women of Diverse Sexual Orientations. Pediatrics. 2018;141(4):e20172278 
Compared with heterosexuals, young women who are sexual minorities (eg, bisexual and lesbian) are at a heightened risk for teen pregnancy (defined as a pregnancy before age 20 years). ${ }^{1-10}$ This population reports established risk factors for teen pregnancy, such as earlier sexual initiation, ${ }^{11}$ more frequently than heterosexuals. It has been suggested that young women who are sexual minorities may be exposed to these established risk factors more often because of their sexual orientation or may even have additional risk factors for teen pregnancy that are unique to sexual minorities. ${ }^{10,12}$ For example, in this research, we suggest that young women who are sexual minorities may try to avoid or cope with the stigma related to their sexual orientation by having sexual intercourse with men, putting themselves at risk for pregnancy. In previous research, data has been leveraged from Canadian adolescents, but there is limited research from the United States in which researchers have empirically examined whether teen pregnancy risk factors vary across sexual orientation groups. ${ }^{13}$ To our knowledge, no authors of US-based studies have explored whether there are additional risk factors that are unique to sexual minorities. Therefore, we examined teen pregnancy risk factors, including a number of potential risk factors that have yet to be explored in previous research, using longitudinal data from young women of diverse sexual orientations in the United States.

The following three proposed risk factors for teen pregnancy were examined among participants of all sexual orientations: (1) childhood maltreatment, (2) bullying victimization and perpetration, and (3) gender nonconformity. The following four risk factors relevant to participants who are sexual minorities were examined among those participants: (4) sexual minority developmental milestones (eg, age at which they first identified as a sexual minority), (5) sexual orientation-related stress (eg, worry that others might think they are lesbian or bisexual), (6) sexual minority outness, and (7) lesbian, gay, and bisexual (LGB) social activity involvement.

Childhood maltreatment is an established risk factor for teen pregnancy ${ }^{14,15}$ and is more common among sexual minorities. ${ }^{16,17}$ Both bullying victimization and perpetration have been associated with an increase in teen pregnancy. ${ }^{18}$ Victims and perpetrators are more likely to experience depression, anxiety, ${ }^{19,20}$ and low self-regard, ${ }^{21}$ which may elevate their teen pregnancy risk. Sexual minorities report being victims and perpetrators of bullying 22,23 more often than their heterosexual peers. Although it has yet to be studied, sexual minorities may engage in sexual behaviors that put them at risk for a teen pregnancy for many reasons, including wanting to "prove" to bully victims or perpetrators that they are heterosexual.

Regarding gender nonconformity, young women who are the most feminine may be at greater risk for having a teen pregnancy. One potential pathway follows the gender intensification hypothesis, ${ }^{24}$ which posits that young people experience increased pressure to conform to culturally sanctioned gender roles during adolescence. Therefore, young women who are the most gender conforming (ie, most feminine) may be the least prepared to negotiate contraception with a male partner, elevating their risk of pregnancy.

It is suggested in the Sexual Minority Stress Theory ${ }^{25}$ that sexual minorities experience stress related to the stigma associated with their sexual orientation. Individuals who reach sexual minority developmental milestones (eg, identifying as mostly heterosexual, bisexual, lesbian, or gay) at younger ages may be exposed to earlier, more persistent stigma and have less well-developed coping skills compared with sexual minorities who reach milestones later. ${ }^{26-28}$ Young women who experience sexual minority stress may seek to strengthen the perception that they are heterosexual by having sexual intercourse with men. Individuals who are not "out" to others about their sexual orientation report lower self-esteem and more anxiety ${ }^{29}$ and may engage in behaviors that put them at risk for a teen pregnancy. Young women who are sexual minorities may view sexual intercourse with men and pregnancy as a way to stay "closeted." Being involved with the LGB community through activities like LGB social or educational events ${ }^{25,30}$ confers social support and may act as a buffer to risk factors. ${ }^{15}$

We hypothesize that the following proposed risk factors would be positively associated with teen pregnancy among young women of all sexual orientations: childhood maltreatment, bullying victimization and perpetration, and gender conformity. Among sexual minorities, we hypothesize that risk factors unique to those participants would be positively associated with teen pregnancy, namely earlier timing of sexual minority developmental milestones, more sexual orientationrelated stress, less outness, and less LGB social activity involvement.

\section{METHODS}

\section{Study Population}

The Growing Up Today Study (GUTS) began in 1996 when women from the Nurses' Health Study 2 enrolled their female and male children ( $N=27793$ ), aged 9 to 14 years, into a longitudinal cohort study. The current analysis was limited to female (based on their sex assigned at birth) GUTS participants who reported their sexual orientation 
TABLE 1 Characteristics by Sexual Orientation in a US-Based Cohort of Young Women $(N=7120)$

\begin{tabular}{|c|c|c|c|c|c|c|}
\hline & $\begin{array}{l}\text { Completely } \\
\text { Heterosexual } \\
\text { With No Same-Sex } \\
\text { Partners }\end{array}$ & $\begin{array}{l}\text { Completely } \\
\text { Heterosexual } \\
\text { With Same-Sex } \\
\text { Partners }\end{array}$ & $\begin{array}{c}\text { Mostly } \\
\text { Heterosexual }\end{array}$ & Bisexual & Lesbian & $p^{a}$ \\
\hline & $84 \%, n=6003$ & $2 \%, n=131$ & $11 \%, n=774$ & $2 \%, n=150$ & $1 \%, n=62$ & \\
\hline \multicolumn{7}{|l|}{ Demographics, \% ( $n)$} \\
\hline Mean age in 1996, y, SD, range: 9-15 y & $11.6,1.6$ & $11.3,1.4$ & $11.3,1.7$ & $11.6,1.7$ & $11.4,1.6$ & $<.0001$ \\
\hline White race and/or ethnicity & $94(5651)$ & $92(120)$ & $91(702)$ & $91(136)$ & $90(56)$ & .001 \\
\hline \multicolumn{7}{|l|}{$\begin{array}{l}\text { Potential risk factors in all participants, } \\
\%(n)\end{array}$} \\
\hline \multicolumn{7}{|l|}{ Childhood gender nonconformity ${ }^{b}$} \\
\hline Below median & $57(3400)$ & $54(71)$ & $44(340)$ & $32(48)$ & $32(20)$ & - \\
\hline Above median, below top decile & $31(1847)$ & $34(45)$ & $34(266)$ & $38(57)$ & $18(1511$ & - \\
\hline Top decile & $13(756)$ & $12(15)$ & $22(168)$ & $30(45)$ & $50(31)$ & $<.0001$ \\
\hline \multicolumn{7}{|l|}{$\begin{array}{l}\text { Childhood physical and/or emotional } \\
\text { abuse, Childhood Trauma } \\
\text { Questionnaire, \% ( } n \text { ) }\end{array}$} \\
\hline Quintile 1, least & $21(945)$ & $15(17)$ & $13(78)$ & $6(7)$ & $10(5)$ & - \\
\hline Quintile 2 & $23(1080)$ & $21(24)$ & $20(123)$ & $13(15)$ & $17(8)$ & - \\
\hline Quintile 3 & 22 (989) & $26(30)$ & $19(116)$ & $16(19)$ & $8(4)$ & - \\
\hline Quintile 4 & 20 (898) & $18(21)$ & $23(142)$ & $24(28)$ & $31(15)$ & - \\
\hline Quintile 5, most & $15(684)$ & $21(24)$ & $26(162)$ & $41(47)$ & $33(16)$ & $<.0001$ \\
\hline \multicolumn{7}{|l|}{$\begin{array}{l}\text { Childhood threatened and/or actual } \\
\text { physical assault, Conflict Tactic } \\
\text { Scales, \% (n) }\end{array}$} \\
\hline Never & $9(408)$ & $10(11)$ & $8(51)$ & $6(7)$ & $13(6)$ & - \\
\hline Rarely or sometimes & 77 (3535) & $72(84)$ & $70(435)$ & $62(72)$ & $71(34)$ & - \\
\hline Often or very often & $14(651)$ & $18(21)$ & $22(135)$ & $32(37)$ & $17(8)$ & $<.0001$ \\
\hline Childhood sexual abuse & $2(106)$ & $7(8)$ & $5(33)$ & $11(12)$ & $4(2)$ & $<.0001$ \\
\hline \multicolumn{7}{|l|}{ Bullying, \% ( $n)$} \\
\hline None & $77(3113)$ & $63(64)$ & $69(373)$ & $59(62)$ & $67(28)$ & - \\
\hline Victim only & $9(358)$ & $6(6)$ & $13(69)$ & $15(16)$ & $17(7)$ & - \\
\hline Perpetrator only & $7(285)$ & $18(18)$ & $8(45)$ & $14(15)$ & $7(3)$ & - \\
\hline Victim and perpetrator & $7(275)$ & $14(14)$ & $10(53)$ & $11(12)$ & $10(4)$ & $<.0001$ \\
\hline \multicolumn{7}{|l|}{$\begin{array}{l}\text { Potential risk factors among participants } \\
\text { who are sexual minorities, } \%(n)\end{array}$} \\
\hline $\begin{array}{l}\text { Sexual minority developmental milestones } \\
\text { Late adolescence and/or young } \\
\text { adulthood }\end{array}$ & $N / A^{d}$ & $N / A^{d}$ & 38 (168) & $20(20)$ & $11(5)$ & - \\
\hline Middle adolescence & $N / A^{d}$ & $N / A^{d}$ & $40(176)$ & $42(43)$ & $44(20)$ & - \\
\hline Early adolescence & $N / A^{d}$ & $N / A^{d}$ & $22(96)$ & $38(39)$ & $44(20)$ & $<.0001$ \\
\hline $\begin{array}{l}\text { Sexual orientation-related stress, } \\
\text { mean, SD }\end{array}$ & $N / A^{d}$ & $N / A^{d}$ & $2.3,1.0$ & $1.9,0.9$ & $1.7,0.8$ & $<.0001$ \\
\hline \multicolumn{7}{|l|}{ Sexual minority outness ${ }^{f}$} \\
\hline Everyone knows & $N / A^{d}$ & $N / A^{d}$ & $9(50)$ & $38(52)$ & $69(36)$ & - \\
\hline Most or a few people know & $N / A^{d}$ & $N / A^{d}$ & 70 (409) & $58(79)$ & $29(15)$ & - \\
\hline No one knows & $N / A^{d}$ & $N / A^{d}$ & 22 (129) & $4(5)$ & $2(1)$ & $<.0001$ \\
\hline \multicolumn{7}{|l|}{ LGB social activity involvement $\$$} \\
\hline$\geq 6$ times per $y$ & $N / A^{d}$ & $N / A^{d}$ & $3(23)$ & $17(24)$ & $56(30)$ & - \\
\hline$<6$ times per y & $N / A^{d}$ & $N / A^{d}$ & $66(462)$ & $72(100)$ & $43(23)$ & - \\
\hline Never & $\mathrm{N} / \mathrm{A}^{\mathrm{d}}$ & $N / A^{d}$ & $31(219)$ & $10(14)$ & $2(1)$ & $<.0001$ \\
\hline \multicolumn{7}{|l|}{ Outcome, \% (n) } \\
\hline Any pregnancy in ages $<20$ y & $2(117)$ & $3(4)$ & $4(28)$ & $9(14)$ & $5(3)$ & $<.0001$ \\
\hline
\end{tabular}

N/A, not applicable; —, $P$ value was calculated for categorical variable

a $P$ value was calculated by using an analysis of variance for continuous variables and $\chi^{2}$ tests for categorical variables (except for teen pregnancy in which it was calculated by using Fisher's exact test)

${ }^{\mathrm{b}}$ Median was based on 4 items from the Recalled Childhood Gender Identity and Gender Role Questionnaire.

${ }^{c}$ Age at which sexual minority identification, same-sex attraction, or same-sex sexual contact first occurred, categorized as late adolescence and/or young adulthood (ages 18-27 y), middle adolescence (ages 14-17 y), or early adolescence (ages $\leq 13 \mathrm{y}$ ).

${ }^{d}$ Data collection among mostly heterosexual, bisexual, and lesbian participants only.

e Sexual orientation-related stress was assessed via questions about the extent to which participants wished they were not attracted to the same sex, with response options 1 (strongly disagree) to 5 (strongly agree); higher scores are used to indicate more stress.

${ }^{\mathrm{f}}$ Mean of 3 items on outness to family, friends, and people at school or work.

8 Mean of 3 items on frequency of LGB social activity involvement. 
and information on the proposed teen pregnancy risk factors between 1996 and $2010(N=7970)$. This study was approved by the Brigham and Women's Hospital Institutional Review Board.

\section{Sexual Orientation}

Detailed information about sexual orientation has been collected on every GUTS questionnaire since 1999 by using an item adapted from the Minnesota Adolescent Health Survey ${ }^{31}$ that asks about feelings of attraction and identity. The item read, "Which of the following best describes your feelings?' ' and included the following response options: completely heterosexual (attracted to persons of the opposite sex), mostly heterosexual, bisexual (equally attracted to men and women), mostly homosexual, completely homosexual (gay or lesbian, attracted to persons of the same sex), and not sure. This item was combined with a question about the sex of sexual partners that read, "During your life, the person(s) with whom you have had sexual contact is (are):" and included the following response options: "I have not had sexual contact with anyone, female(s), male(s), and female(s) and male(s)." These data allowed participants to be categorized by all 3 dimensions of sexual orientation (ie, identity, behavior, and attraction), thereby allowing participants to endorse an identity such as completely heterosexual while also reporting behaviors such as having same-sex partners.

Sexual orientation groups were modeled by using the report at age 19 years (closest to most of the teen pregnancies) as follows: completely heterosexual with no same-sex partners (reference group [ref]), completely heterosexual with same-sex partners, mostly heterosexual, bisexual, and lesbian (made up of the mostly homosexual and completely homosexual groups). We ran sensitivity analyses using the sexual orientation report at age 16 years (preceding most of the teen pregnancies); the results did not reveal meaningful change. For the mediation analyses, the sexual minority groups were collapsed into a single group for statistical power and interpretation ease.

\section{Potential Risk Factors for Teen Pregnancy}

\section{Childhood Maltreatment}

In 2007, participants reported childhood maltreatment before age 11 years. Physical and/or emotional abuse was measured by using 5 items from the Childhood Trauma Questionnaire, ${ }^{32}$ capturing the frequency with which adults in and outside of the family as well as siblings did the following: yelled or screamed, said hurtful or insulting things, punished the child in a way that seemed cruel, hit so hard it left bruises or marks, and made the child feel important (reverse coded). To make comparisons across the literature, we created a score summing across all potential perpetrators and all items, as has been done previously, ${ }^{33}$ to categorize the amount of physical and/or emotional abuse into quintiles. The lowest quintile was used to indicate the least abuse (including none) and the highest quintile was used to indicate the most abuse. Threatened or actual physical assault was measured with 4 items from the Conflict Tactics Scales, ${ }^{34}$ capturing the frequency with which adults in and outside of the family as well as siblings did the following: pushed, grabbed, or shoved; spanked for discipline; and threatened or actually did kick, punch, or hit with something that could hurt or physically attacked in another way. As has been done previously, we combined perpetrator groups and categorized any such reports into: never (ref), rarely or sometimes, and often or very often. Sexual abuse was measured with 2 additional questions. ${ }^{35}$ The first question was about being touched by or forced to touch an adult or older child in a sexual way when the participant did not want to, and a second question asked about an adult or older child forcing or attempting to force sexual activity by threatening, holding down, or hurting the participant. ${ }^{36}$ We considered any participant with such reports as being sexually abused (yes or no). The 3 types of childhood maltreatment (physical and/or emotional abuse, threatened or actual physical assault, and sexual abuse) were all examined separately.

\section{Bullying Victimization and Perpetration}

Using 2 items adapted from the World Health Organization Health Behavior of School-aged Children Survey, ${ }^{37}$ participants reported in 2001 the frequency of past-year bullying victimization and perpetration. Items were measured on a 5-point Likert scale ranging from "I haven't been bullied or I haven't bullied anyone" to "several times a week." We categorized bullying experiences as none, victim only, perpetrator only, or both victim and perpetrator.

\section{Gender Nonconformity}

Participants responded in 2005 and 2007 to 4 items from the Recalled Childhood Gender Identity and Gender Role Questionnaire ${ }^{38}$ about behaviors during childhood up to age 11 years regarding media characters imitated or admired, roles taken in pretend play, favorite toys and games, and feelings of femininity or masculinity. Response options were on a 5-point scale, ranging from "always women or girls or very "feminine"" to "always boys or men or very "masculine.", We calculated a mean of the 4 questions and modeled this into 


\begin{tabular}{|c|c|c|}
\hline & \multicolumn{2}{|c|}{ Teen Pregnancy RR (95\% Cl) } \\
\hline & Individual Variable Modelsa & $\begin{array}{l}\text { Models Simultaneously Adjusted for } \\
\text { Other Significant Variables }{ }^{\text {b }}\end{array}$ \\
\hline \multicolumn{3}{|l|}{ Sexual orientation } \\
\hline Completely heterosexual with no same-sex partners & Ref & Ref \\
\hline Completely heterosexual with same-sex partners & $1.51(0.56-4.03)$ & $1.71(0.62-4.74)$ \\
\hline Mostly heterosexual & $1.78(1.18-2.69)$ & $1.32(0.73-2.37)$ \\
\hline Bisexual & $4.67(2.74-7.97)$ & $2.34(1.14-4.81)$ \\
\hline Lesbian & $2.37(0.76-7.37)$ & $1.14(0.16-8.13)$ \\
\hline \multicolumn{3}{|l|}{ Potential risk factors in all participants } \\
\hline \multicolumn{3}{|l|}{ Childhood gender nonconformityc } \\
\hline Below median & Ref & $N / A^{b}$ \\
\hline Above median, below decile & $0.90(0.64-1.26)$ & $N / A^{b}$ \\
\hline Top decile & $1.00(0.65-1.55)$ & $N / A^{b}$ \\
\hline \multicolumn{3}{|l|}{ Childhood physical and/or emotional abuse } \\
\hline Quintile 1, least & Ref. & Ref \\
\hline Quintile 2 & $0.58(0.29-1.16)$ & $0.52(0.24-1.09)$ \\
\hline Quintile 3 & $0.83(0.43-1.58)$ & $0.62(0.30-1.27)$ \\
\hline Quintile 4 & $1.04(0.56-1.92)$ & $0.62(0.30-1.27)$ \\
\hline Quintile 5, most & $2.30(1.34-3.95)$ & $1.65(0.90-3.03)$ \\
\hline \multicolumn{3}{|l|}{ Childhood threatened and/or actual physical assault } \\
\hline Never & Ref & $N / A^{b}$ \\
\hline Rarely or sometimes & $0.93(0.48-1.77)$ & $N / A^{b}$ \\
\hline Often or very often & $1.33(0.64-2.76)$ & $N / A^{b}$ \\
\hline Childhood sexual abuse & $4.81(2.78-8.32)$ & $2.97(1.52-5.79)$ \\
\hline \multicolumn{3}{|l|}{ Bullying } \\
\hline No bullying involvement & Ref & Ref \\
\hline Victim only & $0.93(0.47-1.85)$ & $0.56(0.22-1.43)$ \\
\hline Perpetrator only & $2.95(1.88-4.63)$ & $2.27(1.30-3.97)$ \\
\hline Victim and perpetrator & $2.40(1.44-4.00)$ & $1.98(1.09-3.62)$ \\
\hline \multicolumn{3}{|c|}{ Potential risk factors among participants who are sexual minorities } \\
\hline \multicolumn{3}{|c|}{ Sexual minority developmental milestones ${ }^{d}$} \\
\hline Late adolescence and/or young adulthood & Ref & $N / A^{b}$ \\
\hline Middle adolescence & $5.67(1.30-24.82)$ & $N / A^{b}$ \\
\hline Early adolescence & $3.15(0.61-16.18)$ & $N / A^{b}$ \\
\hline Sexual orientation-related stress ${ }^{e}$ & $0.97(0.71-1.31)$ & $N / A^{b}$ \\
\hline \multicolumn{3}{|l|}{ Sexual minority outness ${ }^{f}$} \\
\hline Everyone knows & Ref. & $N / A^{b}$ \\
\hline Most or a few people know & $0.86(0.40-1.84)$ & $N / A^{b}$ \\
\hline No one knows & $0.48(0.15-1.54)$ & $N / A^{b}$ \\
\hline \multicolumn{3}{|l|}{ LGB social activity involvement 8} \\
\hline$\geq 6$ times per $y$ & Ref & $N / A^{b}$ \\
\hline$<6$ times per $\mathrm{y}$ & $1.51(0.37-6.22)$ & $N / A^{b}$ \\
\hline Never & $2.14(0.49-9.28)$ & $N / A^{b}$ \\
\hline
\end{tabular}

N/A, not applicable.

a Each model used to assess the association with teen pregnancy is adjusted for age and race and/or ethnicity and is not adjusted for other variables.

${ }^{b}$ The model used to assess the association with teen pregnancy is adjusted for age and race and/or ethnicity and is simultaneously adjusted for the other statistically significant variables (sexual orientation, childhood physical and/or emotional abuse, childhood sexual abuse, and bullying); therefore, the other risk factors do not have any estimate in this model.

${ }^{c}$ Median was based on 4 items from the Recalled Childhood Gender Identity and Gender Role Questionnaire.

d The age at which sexual minority identification, same-sex attraction, or same-sex sexual contact first occurred, categorized as late adolescence and/or young adulthood (ages 18-27 y), middle adolescence (ages 14-17 y), or early adolescence (ages $\leq 13 \mathrm{y}$ ).

e Sexual orientation-related stress was assessed via questions about the extent to which participants wished they were not attracted to the same sex, with response options 1 (strongly disagree) to 5 (strongly agree); higher scores are used to indicate more stress and RR of teen pregnancy for a $1 \mathrm{U}$ change in sexual orientation-related stress.

${ }^{\mathrm{f}}$ Mean of 3 items on outness to family, friends, and people at school or work.

8 Mean of 3 items on frequency of LGB social activity involvement.

tertiles of nonconformity (below median, above median but below top decile, and top decile), so as to not assume linearity, as has been done in previous literature..$^{33}$ Therefore, the participants who are the most gender conforming were categorized below the median and the participants who are the least gender conforming were categorized in the top decile. Data were used from 2005, and we imputed any missing data from 2007.

\section{Sexual Minority Developmental Milestones}

In 2010, 3 items were adapted from the Sexual Risk Behavior Assessment Schedule-Youth ${ }^{39}$ to assess the age at 
TABLE 3 Proportion of Sexual Orientation and Teen Pregnancy Association Mediated by Risk Factors in a US-Based Cohort of Young Women ( $N=7120$ )

\begin{tabular}{|c|c|c|c|c|}
\hline \multirow[t]{2}{*}{ Sexual Orientation } & \multicolumn{4}{|c|}{ Proportion Mediated $(P)$ by Risk Factors } \\
\hline & $\begin{array}{l}\text { Childhood Physical and/ } \\
\text { or Emotional Abuse }\end{array}$ & Childhood Sexual Abuse & Bullying & $\begin{array}{l}\text { Childhood Physical and/or } \\
\text { Emotional Abuse and Sexual } \\
\text { Abuse and Bullying }\end{array}$ \\
\hline Completely heterosexual with no same-sex partners & Ref & Ref. & Ref & Ref \\
\hline Sexual minority ${ }^{a}$ & $0.38(0.01)$ & $0.32(0.03)$ & $N / A^{b}$ & $0.45(0.02)$ \\
\hline
\end{tabular}

N/A, not applicable.

a Sexual minority includes completely heterosexual with same-sex partners, mostly heterosexual, bisexual, and lesbian.

${ }^{\mathrm{b}}$ No mediation.

which the following milestones first occurred among participants who are sexual minorities: identifying as mostly heterosexual, bisexual, lesbian, or gay; sexual attraction to girls; and sexual contact with girls. On the basis of adolescent development and previous literature, ${ }^{27}$ we categorized the youngest age of reaching sexual minority identification, same-sex attraction, or same-sex sexual contact into late adolescence and/or young adulthood (ages 18-27 years), middle adolescence (ages 14-17 years), and early adolescence (ages $\leq 13$ years).

\section{Sexual Orientation-Related Stress}

Answering an item adapted from Wright and Perry's Sexual Identity Distress Scale, ${ }^{40}$ participants who are sexual minorities indicated in 2003 and 2005 on a 1 to 5 scale (" 1 = strongly disagree" to " 5 = strongly agree") the extent to which they wished they were not attracted to the same sex; scores from 2003 to 2005 were averaged, and higher scores were used to indicate more stress.

\section{Sexual Minority Outness}

Answering items adapted from D'Augelli et al, ${ }^{41}$ participants who are sexual minorities indicated in 2003 and 2005 their level of sexual orientation outness to family, friends, and people at school or work using a 5-option scale from "everyone knows" to "no one knows." We created a mean score of these 3 items from both years, categorized as "everyone knows," "most or a few people know," and "no one knows."

\section{LGB Social Activity Involvement}

In 2003 and 2005, 3 items adopted from Rosario et $\mathrm{al}^{42}$ were used to assess the participation in LGB social activities of a participant who is a sexual minority. Participants indicated how often they went to LGB social events, cafes, dance clubs, bars, or hung around these places; went to LGB meetings or educational events at a community center or other place; and read or watched LGB magazines, newspapers, books, Web sites, videos, or movies. A 7-level response option ranged from " 2 or more times per week" to "never" with 5 other middle-response options. We used a mean score of these items from both years and categorized this as occurring $\geq 6$ times per year, $<6$ times per year, or never.

It is possible that some of the proposed risk factors, including bullying victimization and perpetration, sexual orientationrelated stress, and LGB social activity involvement were reported after some participants' pregnancies, so we ran sensitivity analyses excluding any individuals whose pregnancies occurred after the report of these factors; the results did not reveal meaningful change.

\section{Teen Pregnancy}

In 1999, lifetime histories of pregnancy were collected from all participants; in each subsequent questionnaire, current pregnancies have been queried. As is done in the literature, ${ }^{43}$ participants who had any pregnancies occurring before age
20 years were categorized as ever having a teen pregnancy.

\section{Confounders}

Potential confounders included baseline age in years (continuous) and race and/or ethnicity (white, another race and/or ethnicity). In sensitivity analyses, we explored whether estimates significantly changed when adjusting for other covariates, such as region of residence at age 19 years (the report closest to most of the teen pregnancies), coded as West, Midwest, South, or Northeast; the results did not reveal meaningful change. Missing data on all potential cofounders were $<0.01 \%$, so we used a complete case approach.

\section{Statistical Analysis}

First, we examined the association between sexual orientation, the potential risk factors, and teen pregnancy using bivariate models. Then, we used multivariate regression from log-binomial models adjusted for potential confounders. To account for sibling clusters, we estimated the variance using generalized estimating equations with a compound symmetry working correlation matrix. To examine if each variable was a risk factor for teen pregnancy, we fit models for each individual potential risk factor, resulting in risk ratios (RRs) and 95\% confidence intervals (CIs). We also fit a model simultaneously adjusting for the variables that were statistically significant risk factors. Finally, we calculated the percent 
of the sexual orientation and teen pregnancy association mediated by the statistically significant risk factors using the publicly available $\%$ mediate macro ${ }^{44}$. All analyses were conducted by using SAS version 9.3 (SAS Institute, Inc, Cary, NC).

\section{RESULTS}

Of the 7120 participants in our sample, $84 \%(n=6003)$ identified as completely heterosexual with no samesex partners, $2 \%(n=131)$ identified as completely heterosexual with samesex partners, $11 \%(n=774)$ identified as mostly heterosexual, $2 \%(n=150)$ identified as bisexual, and 1\% $(n=62)$ identified as lesbian.

Compared with completely heterosexuals with no samesex partners, sexual minorities experienced more childhood maltreatment, more bullying victimization and perpetration, and greater gender nonconformity. Among participants who are sexual minorities, lesbians reached sexual minority developmental milestones at the youngest age, whereas bisexual and mostly heterosexuals reported the highest amounts of sexual orientation-related stress, being the least out about their sexual orientation, and having the least LGB social activity involvement (Table 1).

A total of $2 \%(n=166)$ of participants had a teen pregnancy. Compared with completely heterosexuals with no same-sex partners, there was not a statistically significant elevated risk of a teen pregnancy for completely heterosexuals with same-sex partners (RR: 1.51; 95\% CI: 0.584.03), but mostly heterosexuals (RR: 1.78; 95\% CI: 1.18-2.69) and lesbians (RR: 2.37; 95\% CI: 0.76-7.37) had $\sim 2$ times the risk, and bisexuals (RR: 4.67; 95\% CI: 2.74-7.97) had nearly 5 times the risk (Table 2).

In individual models, childhood maltreatment and bullying victimization and perpetration were each associated with teen pregnancy. After simultaneously adjusting for the significant risk factors, the sexual orientation-related teen pregnancy disparities were attenuated (Table 2). When testing for mediation, 38\% of the disparity was explained by physical and/or emotional abuse, and $32 \%$ of the disparity was explained by childhood sexual abuse. Bullying was not a statistically significant mediator. Together, childhood maltreatment and bullying explained $45 \%$ of the sexual orientation-related teen pregnancy disparity (Table 3).

In individual models of the potential risk factors unique to sexual minorities, reaching sexual minority developmental milestones earlier was associated with an increase in teen pregnancy (Table 2). Because data were available only among sexual minorities, no further mediation analyses were conducted for those risk factors.

None of the sensitivity analyses (modeling sexual orientation at age 16 years, excluding pregnancies that occurred before the proposed risk factor was assessed, and adjusting for geographic region) made any meaningful differences in the results.

\section{DISCUSSION}

Young women who are sexual minorities in this cohort, particularly bisexuals, were significantly more likely than their heterosexual peers to experience a teen pregnancy. The higher teen pregnancy prevalence among sexual minorities was partially explained by childhood maltreatment and bullying. One additional variable, the earlier age of sexual minority developmental milestones, was a significant risk factor for teen pregnancy among sexual minorities.

With these findings, we build on the existing research about sexual orientation-related teen pregnancy disparities. For example,
Saewyc et al $^{10}$ examined teen pregnancy risk factors across sexual orientation groups using data from teens in British Columbia, Canada. In addition to established teen pregnancy risk factors, the authors examined factors that may be unique to sexual minorities. Compared with heterosexual peers, female participants who are sexual minorities experienced sexual initiation at an earlier age and were more likely to have been sexually abused, both of which are teen pregnancy risk factors. Our results from previous analyses support the finding of an earlier age at sexual initiation for young women who are sexual minorities, ${ }^{11}$ and the current study supports the sexual abuse finding.

In that same study, Saewyc et $\mathrm{al}^{10}$ were also able to calculate an enacted stigma (defined as the exclusion, harassment, discrimination, and violence resulting from the disclosure or even suspicion of a sexual minority identity) composite score, including information on the following: experiencing discrimination on the basis of race, physical appearance, or sexual orientation; being excluded by others at school, being insulted or teased, or being physically assaulted; or experiencing verbal or physical sexual harassment. Compared with participants who are sexual minorities without teen pregnancies, participants with teen pregnancies reported more sexual orientation-based discrimination and a higher enacted stigma score. In the current study, we did not have available data on sexual orientation-related discrimination to make such a comparison. However, the higher prevalence of childhood maltreatment and bullying in our participants who are sexual minorities relative to heterosexuals may, in part, stem from sexual orientation-related discrimination.

In another study that was based on data from Canadian teens and health 
care providers, Travers et $\mathrm{al}^{12}$ used qualitative data to examine teen pregnancy risk factors. The focus groups discussed several potential risk factors, many of which stemmed from heterosexism. For example, male and female participants spoke about a lack of sexual health information directed toward sexual minorities, including limited knowledge about their risk of having or being involved in a teen pregnancy. Participants also mentioned teens who are sexual minorities feeling a desire to prove their heterosexuality or hide their sexual minority status or even conform to heterosexual norms through sexual activity with a different gender or sex.

Goldberg et al $^{13}$ used the US-based National Longitudinal Study of Adolescent to Adult Health data to examine how certain established teen pregnancy risk factors attenuate sexual orientation disparities. As in the current study, sexual orientationrelated teen pregnancy disparities in that cohort were partially attenuated by factors such as a history of childhood sexual abuse.

The current study does have some limitations. GUTS data were not available on sexual orientation-based discrimination or on the measures needed to create an enacted stigma score. However, we examined novel factors that had yet to be explored, including gender nonconformity, sexual minority developmental milestones, sexual orientationrelated stress, sexual minority outness, and LGB social activity involvement. Whereas bullying has been a focus in previous research, we were able to look at this with more nuance by examining not only bullying victimization but also bullying perpetration, which proved to be a strong teen pregnancy risk factor in this sample. Similarly, childhood maltreatment has been the focus in previous research, but our data allowed us to examine differences in the type of abuse.

The GUTS participants were children of Nurses' Health Study 2 participants, so results from this sample may not generalize to other populations; this cohort is predominantly of white race and/or ethnicity, their mothers are all nurses, and the majority of participants' annual household incomes during their childhood was $\geq \$ 75000$. Teen pregnancy is a relatively rare outcome in this sample, which limits the statistical power. It is possible that we lacked the data to detect small- to moderate-sized associations for some of the proposed risk factors; future researchers should test these factors with an even larger sample size. Data on teen pregnancy risk factors were available for young women only, so future researchers should explore teen pregnancy involvement among young men who are sexual minorities as well.

\section{CONCLUSIONS}

Teen pregnancy prevention efforts should focus on risk factors such as childhood maltreatment and bullying among young people of all sexual orientations. These risk factors are more common among young women who are sexual minorities compared with heterosexual peers; therefore, this focus can help to reduce the existing sexual orientation-related teen pregnancy disparity. Future researchers should explore how these risk factors and others that are unique to sexual minorities (eg, reaching sexual minority developmental milestones earlier) may be linked to sexual orientationbased discrimination and stigma; such data can inform teen pregnancy prevention efforts.

Reproductive Investigation Scientific Meeting; March 25-28, 2015; San Francisco, California; and the Society for Adolescent Health and Medicine Annual Meeting; March 18-21, 2015; Los Angeles, California.

DOI: https://doi.org/10.1542/peds.2017-2278

Accepted for publication Dec 27, 2017

Address correspondence to Brittany M. Charlton, ScD, Division of Adolescent and Young Adult Medicine, Boston Children's Hospital, 300 Longwood Ave, Boston, MA 02115. E-mail: bcharlton@mail.harvard.edu

PEDIATRICS (ISSN Numbers: Print, 0031-4005; Online, 1098-4275).

Copyright (C) 2018 by the American Academy of Pediatrics

FINANCIAL DISCLOSURE: The authors have indicated they have no financial relationships relevant to this article to disclose.

FUNDING: Dr Charlton was supported by grant F32HD084000, Dr Katz-Wise by grant K99HD082340, Drs Rosario and Austin by grant R01HD057368, and Dr Austin by grant R01HD066963 from the Eunice Kennedy Shriver National Institute of Child Health and Human Development. Dr Calzo was supported by grant K01DA034753 from the National Institute on Drug Abuse. Additional funds were provided to Dr Charlton by the Society of Family Planning through an Interdisciplinary Innovation grant and the American Cancer Society through grant MRSG CPHPS 130006. Funded by the National Institutes of Health (NIH).

POTENTIAL CONFLICT OF INTEREST: The authors have indicated they have no potential conflicts of interest to disclose. 


\section{REFERENCES}

1. Flicker S, Flynn S, Larkin J, et al. Sexpress: The Toronto Teen Survey Report. Toronto, 0N: Planned Parenthood Toronto; 2009

2. Hartnett CS, Lindley LL, Walsemann KM Congruence across sexual orientation dimensions and risk for unintended pregnancy among adult US women. Womens Health Issues. 2017;27(2): 145-151.e2

3. Riskind RG, Tornello SL, Younger BC, Patterson CJ. Sexual identity, partner gender, and sexual health among adolescent girls in the United States. Am J Public Health. 2014;104(10):1957-1963

4. Blake SM, Ledsky R, Lehman T, Goodenow C, Sawyer R, Hack T. Preventing sexual risk behaviors among gay, lesbian, and bisexual adolescents: the benefits of gaysensitive HIV instruction in schools. Am J Public Health. 2001;91(6):940-946

5. Case P, Austin SB, Hunter DJ, et al. Sexual orientation, health risk factors, and physical functioning in the Nurses' Health Study II. J Womens Health (Larchmt). 2004;13(9):1033-1047

6. Charlton BM, Corliss HL, Missmer SA, Rosario M, Spiegelman D, Austin SB. Sexual orientation differences in teen pregnancy and hormonal contraceptive use: an examination across 2 generations. Am J Obstet Gynecol. 2013;209(3):204.e1-e8

7. Goodenow C, Szalacha LA, Robin LE, Westheimer K. Dimensions of sexual orientation and HIV-related risk among adolescent females: evidence from a statewide survey. Am J Public Health. 2008;98(6):1051-1058

8. Lindley LL, Walsemann KM. Sexual orientation and risk of pregnancy among New York City high-school students. Am J Public Health. 2015;105(7):1379-1386

9. Saewyc EM, Bearinger LH, Blum RW, Resnick MD. Sexual intercourse, abuse and pregnancy among adolescent women: does sexual orientation make a difference? Fam Plann Perspect. 1999;31(3):127-131

10. Saewyc EM, Poon CS, Homma Y, Skay CL. Stigma management? The links between enacted stigma and teen pregnancy trends among gay, lesbian, and bisexual students in British Columbia. Can J Hum Sex. 2008;17(3):123-139

11. Charlton BM, Corliss HL, Missmer SA, et al. Reproductive health screening disparities and sexual orientation in a cohort study of US adolescent and young adult females. J Adolesc Health. 2011;49(5):505-510

12. Travers R, Newton H, Munro L. "Because it was expected": heterosexism as a determinant of pregnancy among sexually diverse youth. Can J Commun Ment Health. 2011;30(2):65-79

13. Goldberg SK, Reese BM, Halpern CT. Teen pregnancy among sexual minority women: results from the National Longitudinal Study of adolescent to adult health. $J$ Adolesc Health. 2016;59(4):429-437

14. Noll JG, Shenk CE. Teen birth rates in sexually abused and neglected females. Pediatrics. 2013;131(4) Available at: www.pediatrics.org/cgi/ content/full/131/4/e1181

15. Saewyc EM, Taylor D, Homma Y, Ogilvie G. Trends in sexual health and risk behaviours among adolescent students in British Columbia. Can J Hum Sex. 2008;17(1-2):1-13

16. Saewyc EM, Skay CL, Pettingell SL, et al. Hazards of stigma: the sexual and physical abuse of gay, lesbian, and bisexual adolescents in the United States and Canada. Child Welfare. 2006;85(2):195-213

17. Corliss HL, Cochran SD, Mays VM. Reports of parental maltreatment during childhood in a United States population-based survey of homosexual, bisexual, and heterosexual adults. Child Abuse Negl. 2002;26(11):1165-1178

18. Lehti V, Sourander A, Klomek A, et al. Childhood bullying as a predictor for becoming a teenage mother in Finland. Eur Child Adolesc Psychiatry. 2011;20(1):49-55

19. Hawker DS, Boulton MJ. Twenty years' research on peer victimization and psychosocial maladjustment: a metaanalytic review of cross-sectional studies. J Child Psychol Psychiatry. 2000;41(4):441-455
20. Arseneault L, Walsh E, Trzesniewski K, Newcombe R, Caspi A, Moffitt TE. Bullying victimization uniquely contributes to adjustment problems in young children: a nationally representative cohort study. Pediatrics. 2006;118(1):130-138

21. Egan SK, Perry DG. Does low selfregard invite victimization? Dev Psychol. 1998;34(2):299-309

22. Berlan ED, Corliss HL, Field AE, Goodman E, Austin SB. Sexual orientation and bullying among adolescents in the growing up today study. J Adolesc Health. 2010;46(4):366-371

23. Schneider SK, O'Donnell L, Stueve A, Coulter RW. Cyberbullying, school bullying, and psychological distress: a regional census of high school students. Am J Public Health. 2012;102(1):171-177

24. Hill JP, Lynch ME. The intensification of gender-related role expectations during early adolescence. In: BrooksGunn J, Petersen AC, eds. Girls at Puberty. Boston, MA: Springer; 1983:201-228

25. Meyer IH. Prejudice, social stress, and mental health in lesbian, gay, and bisexual populations: conceptual issues and research evidence. Psychol Bull. 2003;129(5):674-697

26. Corliss HL, Cochran SD, Mays VM, Greenland S, Seeman TE. Age of minority sexual orientation development and risk of childhood maltreatment and suicide attempts in women. Am J Orthopsychiatry. 2009;79(4):511-521

27. Katz-Wise SL, Rosario M, Calzo JP, Scherer EA, Sarda V, Austin SB Associations of timing of sexual orientation developmental milestones and other sexual minority stressors with internalizing mental health symptoms among sexual minority young adults. Arch Sex Behav. 2017;46(5):1441-1452

28. Parks CA, Hughes TL. Age differences in lesbian identity development and drinking. Subst Use Misuse. 2007:42(2-3):361-380

29. Jordan KM, Deluty RH. Coming out for lesbian women: its relation to 
anxiety, positive affectivity, self-esteem, and social support. $J$ Homosex. 1998;35(2):41-63

30. Kertzner RM, Meyer IH, Frost DM, Stirratt MJ. Social and psychological well-being in lesbians, gay men, and bisexuals: the effects of race, gender, age, and sexual identity. Am J Orthopsychiatry. 2009;79(4):500-510

31. Remafedi G, Resnick M, Blum R, Harris L. Demography of sexual orientation in adolescents. Pediatrics. 1992;89(4, pt 2):714-721

32. Bernstein DP, Stein JA, Newcomb MD, et al. Development and validation of a brief screening version of the Childhood Trauma Questionnaire. Child Abuse Negl. 2003;27 (2):169-190

33. Roberts AL, Rosario M, Corliss HL, Koenen KC, Austin SB. Elevated risk of posttraumatic stress in sexual minority youths: mediation by childhood abuse and gender nonconformity. Am J Public Health. 2012;102(8):1587-1593

34. Straus MA, Hamby SL, Boney-McCoy $S$, Sugarman DB. The revised Conflict Tactics Scales (CTS2): development and preliminary psychometric data. J Fam Issues. 1996;17 (3):283-316

35. Moore D, Gallup G, Schussel R. Disciplining Children in America: A Gallup Poll Report. Princeton, NJ: The Gallup Organization; 1995

36. Koss MP, Gidycz CA. Sexual experiences survey: reliability and validity. J Consult Clin Psychol. 1985;53(3):422-423

37. Due P, Holstein BE, Lynch J, et al; Health Behaviour in School-Aged Children Bullying Working Group. Bullying and symptoms among school-aged children: international comparative cross sectional study in 28 countries. Eur J Public Health. 2005;15(2):128-132

38. Zucker KJ, Mitchell JN, Bradley SJ, Tkachuk J, Cantor JM, Allin SM. The recalled childhood gender identity/gender role questionnaire: psychometric properties. Sex Roles. 2006;54(7-8):469-483

39. Meyer-Bahlburg HFL, Exner TA, Exner TM, Gruen RS. Sexual Risk Behavior Assessment Schedule-Youth. New York, NY: New York State Psychiatric Institute; 1994
40. Wright ER, Perry BL. Sexual identity distress, social support, and the health of gay, lesbian, and bisexual youth. $\checkmark$ Homosex. 2006;51(1):81-110

41. D’Augelli AR, Hershberger SL, Pilkington NW. Lesbian, gay, and bisexual youth and their families: disclosure of sexual orientation and its consequences. Am J Orthopsychiatry. 1998;68(3):361-371; discussion 372-375

42. Rosario M, Hunter J, Maguen S, Gwadz M, Smith R. The coming-out process and its adaptational and health-related associations among gay, lesbian, and bisexual youths: stipulation and exploration of a model. Am J Community Psychol. 2001;29(1):133-160

43. Romero L, Pazol K, Warner L, et al. Reduced disparities in birth rates among teens aged 15-19 years-United States, 2006-2007 and 2013-2014. MMWR Morb Mortal Wkly Rep. 2016;65(16):409-414

44. Hertzmark E, Pazaris M, Spiegelman D. \%mediate [computer program]. 2009. Available at: https://www.hsph.harvard. edu/donna-spiegelman/software/ mediate/ 